\title{
TİCARİ ARAÇLARDA TAVAN EŞYA RAFININ ERGONOMİ KONTROLÜ İÇİN PARAMETRÍK MODEL TASARIMI
}

\author{
Nebibe ŞENTÜRK PALA ${ }^{*}$, Salih GÜLER ${ }^{2}$ \\ ${ }^{1}$ TOFAŞ Türk Otomotiv Fabrikası A.Ş., ORCID No: http://orcid.org/0000-0001-7506-8470 \\ 2 TOFAŞ Türk Otomotiv Fabrikası A.Ş., ORCID No: http://orcid.org/
}

\begin{abstract}
Anahtar Kelimeler
Öz

Parametrik tasarım

Otomobil geliştirme sürecinde, sürücü ve yolcuların araç içindeki objelere erişme

Bilgi tabanlı mühendislik

kolaylığı ve rahatlığı için en uygun ürün tasarımı elde edilebilmesi hedeflenmektedir.

Araç içi yolcu yerleşimi

$\mathrm{Bu}$ çalışma ile bilgisayar destekli tasarım (CAD) programında insan antropometrik

CAD yeniden kullana

bilirliği

Otomotiv

değerlerine göre ticari otomobillerde kullanılan tavan eşya rafinın ergonomi kontrolü için parametrik tasarım tekniğine dayalı bir kontrol metodu geliştirilmiştir.

Mühendisleri Derneği

Otomobil iç yaşam alanına ait tasarım geliştirme sürecinde, SAE J826 (SAE J4002) dokümanından yararlanılarak araç içi yolcu yerleşiminde ergonomik açıdan ulaşabilirlik, oturabilirlik ve görebilirlik gibi ergonomi parametreleri tanımlanmıştır. Sürücü veya yolcular için hedeflenen ergonomi değerleri elde edilene kadar tasarım ve geliştirme sürecine devam edilmiştir

Geleneksel kontrol yöntemlerine klyasla bu gelistirilen yeni metot ile ergonomi kontrol sonuçlarındaki hataların azalmasıyla sürecin güvenilirliğinin arttı̆̆ ve analiz sürecinin standartlaştırarak kontrollere hız kazandırıldığı gözlemlenmiștir. Bu makalede, geliştirilen yeni şablon ile sürücü araç içindeki tavan eşya rafina ulaşıbilirlik durumunun incelenmesi ve yorumlanması anlatılmaktadır.
\end{abstract}

\section{PARAMETRIC DESIGN FOR ERGONOMICS CONTROL OF THE ROOF SHELF IN THE COMMERCIAL VEHICLES}

\begin{tabular}{l}
\hline Keywords \\
\hline Parametric design \\
Knowledge \\
based engineering (KBE) \\
Vehicle occupant packaging \\
(VOP) \\
CAD reusability \\
Society \\
automotive engineers (SAE)
\end{tabular}

\section{Abstract}

In the automobile development process, it is aimed to obtain the most suitable product design for the ease and comfort of the driver and passengers to access the objects inside the vehicle. With this study, a control method based on a parametric design technique has been developed for the ergonomics control of the ceiling rack used in commercial cars according to human anthropometric values in the computer-aided design (CAD) program.

Ergonomic parameters such as ergonomic accessibility, seating, and visibility in the passenger compartment of the vehicle have been defined by using the document SAE J826 (SAE J4002) in the design development process of the automobile interior living space. The design and development process continued until the ergonomics values targeted for the driver or passengers were achieved.

Compared to traditional control methods, it has been observed that with the new method developed, the errors in ergonomics control results decrease and the reliability of the process increases, and the controls are accelerated by standardizing the analysis process. In this article, with the new template developed, the examination and interpretation of the accessibility status of the roof rack inside the driver-vehicle is explained.

\begin{tabular}{llll}
\hline Araştırma Makalesi & & Research Article & \\
Başvuru Tarihi & $: 11.11 .2019$ & Submission Date & $: 11.11 .2019$ \\
Kabul Tarihi & $: 08.04 .2020$ & Accepted Date & $: 08.04 .2020$ \\
\hline
\end{tabular}

\footnotetext{
*Sorumlu yazar e-posta: nebibe.pala@tofas.com.tr
} 


\section{Giriş}

Otomotiv sektörü, ana sanayiden tedarikçi firmasına kadar küresel piyasa şartlarına göre yoğun bir rekabet içerisindedir. Bu rekabet ortamında yeni bir otomobilin pazara girebilmesi ve pazarda kalabilmesi için mevcutta uygulanan proje süreçlerinin kapsamlarının iyileştirilmesi ve sürelerinin kısaltılması çok önem kazanmıştır.

Bir otomobil projesi, kurgu sürecinden seri üretim sürecine kadar, pazar gereksinimleri tanımlanıp, ön tasarım aşaması ile başlayarak, ayrıntılı tasarım aşamasına ve dijital modellere kadar uzanan uzun ve karmaşık bir tasarım etkinliği ile ilişkilidir (Yannick, 2013). Otomobil tasarım sürecinde, tasarlanan dijital modellerin proje hedef değerlerine göre seri üretim sürecine kadar doğrulanması ve çıkabilecek hataların çözümlenmesi gerekmektedir.

Otomobil üzerinde bulunan parçaların tasarım sürecinde, parçaların en önemli tasarım parametrelerinden birisi olan kabin içi yolcu konforuna ait ergonomi hedef değerlerinin belirlenmesiyle başlanmaktadır. Tasarımcı bu belirlenen ergonomi hedef değerlerini sağlayacak tasarımı elde etmek üzerine bilgisayar destekli tasarım (CAD) programlarında, araç üzerinde montajı yapılabilecek düzeyde olana kadar yani kabul edilebilir modellemeleri yapana kadar devam etmektedir.

Otomotiv şirketinin tasarım veri tabanında araç ve parça tasarlamak ve değerlendirmek için birçok kurum içi prosedür ve rehber olmasına rağmen, Otomotiv Mühendisleri Derneği (SAE) tarafından önerilen uygulamalar birçok genel tasarım prosedürünün temelini oluşturmaktadır. $\mathrm{Bu}$ uygulamaların arasında şekilde gösterildiği gibi önemli bir ilişki vardır (Tablo 1, Şekil 1) (Matthew, 1999).

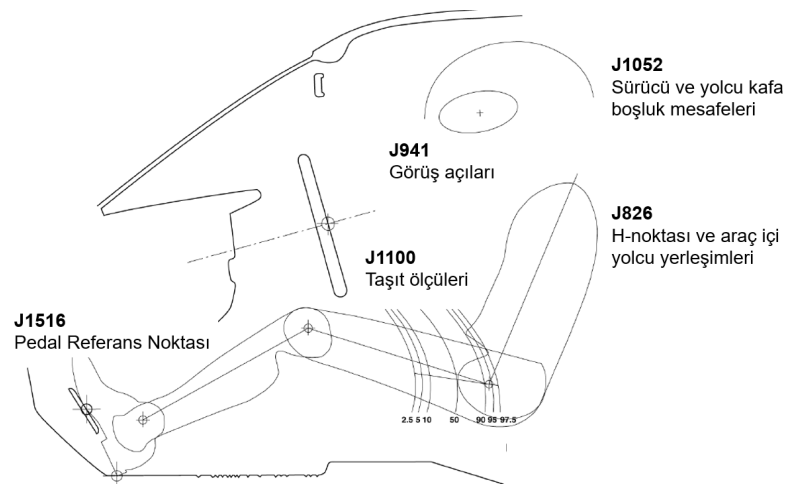

Şekil 1. SAE Araç İç Tasarımı İçin Kullanılan Uygulamalar
Tablo 1. SAE Araç İçi Yolcu Konforu İçin Kullanilan Uygulamalar

\begin{tabular}{|c|c|}
\hline Kod & Konu \\
\hline J182 & Araç koordinat sistemi \\
\hline $\mathrm{J} 287$ & Sürücü erişim mesafeleri \\
\hline J826 & $\begin{array}{l}\text { H-noktası ve araç içi yolcu } \\
\text { yerleşimleri }\end{array}$ \\
\hline J941 & Sürücü görüș açıları \\
\hline $\mathrm{J} 1052$ & $\begin{array}{l}\text { Sürücü ve yolcu kafa boşluk } \\
\text { mesafeleri }\end{array}$ \\
\hline $\mathrm{J} 1100$ & Araç boyutları \\
\hline $\mathrm{J} 1516$ & Pedal referans noktaları \\
\hline
\end{tabular}

Her türlü araç ve gereç kullanıcılarının (yaş ve cinsiyetlerine göre değişiklik gösteren) boyut farklılıklarını gözeterek (insan-çevre için arakesit) tasarımları yapmak için Antropometri biliminden yararlanılır. Yunanca antropos (insan) ve metikos (ölçü) sözcüklerinden oluşan Antropometri, insan vücut ölçülerinin belirlenmesi ve uygulanması ile uğraşan bir bilim dalıdır. Mühendislik Antropometri ise ergonominin en önemli konularındandır ki insan ölçülerini mühendislik açısından değerlendirerek inceler (Kahraman, 2013).

Antropometrik verilerin ilk konsept aşamasında kullanılması, daha sonra yapılması pahalı olan boyut ve şekil değişikliklerini en aza indirmektedir. Antropometri bilgisini etkin bir şekilde kullanmak için, insan vücudu ile giyilen veya kullanılan eşyalar arasındaki ilişkiler hakkında bilgi sahibi olmak önemlidir (Robinette, 2012).

Antropometrik veriler coğrafi konumlarına göre insanlar boyutlarıyla çeşitli yüzdelik dilimlere (Persentil) ayrılarak kayıt altına alınmıştır (Şekil 2). (Güler, 2016). Antropometri verilerine göre ürün tasarımı șekillenmektedir.

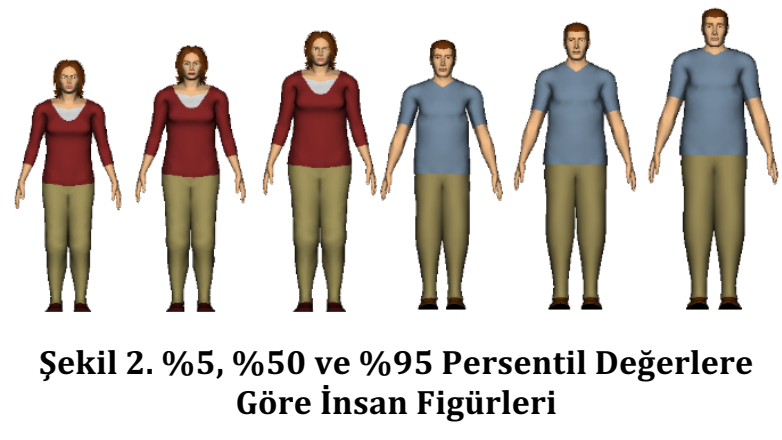


Geleneksel kontrol yöntemlerinde proje sürecinde otomobile ait parça tasarımları ve bu tasarımlara ait doğrulama süreci kişilerin yorumlama ve tasarım kabiliyetlerine göre tamamlanabilmektedir. Tamamlanan bir parça tasarımı çevre parça tasarımlarıyla haberleşmediği için oluşabilecek hatalar öngörülememektedir. Bu hatalar tasarım ve doğrulama sürecinde, projenin planlama aşamasında ön görülmemiş zaman kayıpları yaşatabilir ve böyle bir durumda ise projenin bitiş tarihinde gecikmeler yaşanabilir.

Geri dönüşlerin sıkça yaşandığı söz konusu süreç bu yüzden projenin boyutuna bağlı olarak 4-5 ay gibi uzun bir zaman dilimini kapsamaktadır (Utanır, vd., 2000).

Geleneksel kontrol yöntemlerinde aksine bilgi tabanlı mühendislik (KBE) metodu, bilgisayar destekli tasarım programında (CAD) bilgiyi depolayabilen, istenildiğinde depolanan alana ulaşarak bilgiyi kullanabilen, depolanan bilginin değișimi durumunda güncellenmesine izin veren ve bu metot ile oluşturulan modellerin kendi arasında haberleşmesine olanak sağlayan parametrik bir tasarımdır yöntemidir (Şekil 3).

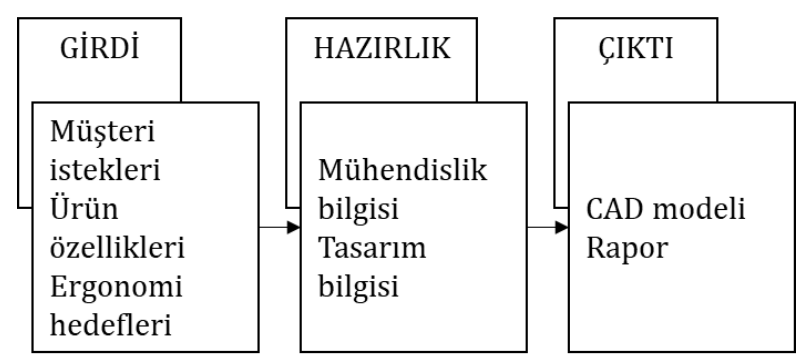

Şekil 3. KBE Sistemi Akış Diyagramı

Tasarım sürecinde süre kayıplarının engellenebilmesi ve mevcut duruma göre kısa sürede tamamlanabilmesi için kişilerden bağımsız olarak kullanılabilecek, modellerin birbiriyle haberleşebileceği parametrik tasarımlara ihtiyaç duyulmaktadır. Parametrik modelleme "değişim ve yeniden kullanım için gereken zamanı ve çabayı" azaltmaktadır (Aish ve Woodbury, 2005).

Parametrik tasarım, bir bütünü oluşturan elemanların sahip oldukları özelliklere, parametrik tasarım değişkenleri olarak belirlenen değerlere, ihtiyaçlar doğrultusunda yeni değerlerin aktarılması işlemi olarak tanımlanabilir. Parametrik tasarım ile önceden oluşturulan modellerin yeniden boyutlandırılması ve değiştirilmeleri daha kolaydır (Karabıyık, 2011).
Bilgi tabanlı mühendislik (KBE) yaklaşımıyla, ürün geliștirme sürecini zaman ve maliyetini düşürmek amacıyla ürün ve süreç mühendisliği bilgisini yakalamak ve sistematik olarak yeniden kullanmak için KBE sistemleri adı verilen özel yazılım araçlarının kullanımına dayanan bir teknolojidir (Rocca, 2012).

Bilgisayar destekli tasarım ve mühendislik uygulamalarında kullanılan metotlar; parametrik tasarım ve bilgi tabanlı mühendislik içermektedir. Bilgisayar destekli tasarım yapan yazılımların çoğu geometrik modellerde parametrik tasarım yapmaya olanak sağlamaktadır (Andrews, 1999).

Endüstriyel açıdan bakıldığında, özellikle parametrik tasarım ile şu anda geometrik modeller ve montajlar oluşturmak için endüstriyel standart olan bir teknolojidir ve birçok mühendislik alanında yaygın olarak kullanılmaktadır (Camba ve Contero, 2016).

\section{Mevcut Yöntem}

Yeni bir ticari otomobil projesinde kabin için sürücü ve yolcuların konforunu, hedeflenen ergonomi değerleri içerisinde tutabilmek için önemli olan 62 adet kritik parçanın ergonomi analizleri yapılmaktadır. Bu kontroller kurgu sürecinden nihai ürünü elde edene kadar tekrarlanmaktadır. Proje süresince kontrolü yapılan parçalardan biri tavan bölgesinde sabitlenen tavan eşya rafıdır. $\mathrm{Bu}$ parça kullanıcıya mevcut araç bagajı haricinde kullanabileceği ek bir saklama alanı yaratmaktadır.

Tavan eşya rafı için sanal ortam da ergonomi doğrulaması yapılabilmesi için bilgisayar destekli tasarım programında (CAD) iki veya üç boyutlu Jack adı verilen ölçüm mankenlerinin oluşturulması gerekmektedir. $\mathrm{Bu}$ mankenler, gövde ve bacak arasında dönme merkezinde bulunan $\mathrm{H}$ noktası olarak tanımlanan sürücü veya yolcuların kabin içinde oturma pozisyonlarını (X, Y ve Z koordinatları) tanımlamaktadır. Sürücü için projeye özel ergonomi değerleri temin edilerek, bilgisayar destekli tasarım programında (CAD) oluşturulmaları veya pozisyonlanmaları ve analizlerinin tamamlanması tavan eşya rafı kontrolü için yaklaşık 18 saatte gerçekleştirilebilmektedir.

Literatürde var olan çalışmalar incelendiğinde parametrik tasarım ve yeniden kullanılabilir tasarım ile ilgili tez, makale ve kitap olduğu tespit edilmiştir. $\mathrm{Bu}$ çalışmada, ticari araçlarda bulunan tavan eşya rafı için ergonomi doğrulaması sırasında daha kolay ve daha hızlı doğrulama yapabilecek bir sistem geliștirilmiștir. 


\section{Geliştirilen Yöntem}

Sanal ortamda bilgisayar destekli tasarım (CAD) programı olan TCAE/UG ortamında çalışan şablon parametrik tasarım metoduna (KBE) dayanmaktadır. Bu sistemde girdi olarak Fiat Doblo projesi ergonomi hedef değerleri ile Fiat firmasının geçmiş tecrübelerinden elde edilen bilgi birikimi harmanlanmakta ve çıktı olarak tavan eşya rafının tasarım geliştirme sürecinde ve ergonomi kontrol sürecinde kullanabilecek bir yöntem geliştirilmiştir. $\mathrm{Bu}$ çalışma ile farklı ergonomi beklentileri olan tasarımlara ait kontrol süreçleri kolaylıkla tamamlanabilmektedir. Aynı parametrik modeller, farklı bir projenin ergonomi hedef değerlerine göre değiştirilerek tekrardan kullanılabilecektir. Bu süreçte bu şablonun çıktısının girdi olarak kullanıldığı diğer şablonlar ise eş zamanlı olarak güncellenebilecektir.

Parametrik tasarım sürecine başlamadan önce sürecin akışı için bir kurgu bir yol haritası oluşturulması önemlidir. Böylelikle sonuca kolayca ulaşılabilmesi sağlanmış olur. Yol haritası beş ana aşamadan oluşur (Yannick, 2013).

- Standardizasyon.

- Metodoloji.

- Genel modelleme.

- Uzman kuralları.

- Otomasyon

\subsection{Standartlaştırma}

Bir veya birden fazla parametrik şablonun kendi aralarında sorunsuz olarak iletişim kurarak güncellenebilmesi için sistematik bir yapıya ihtiyacı vardır. Tavan eşya rafına ait parametrik şablon tasarım sürecine başlamadan önce TCAE/UG ortamında parametrik şablon için montaj yapısı oluşturulmalıdır. Parametrik tasarım yapısı girdi, hazırlık ve çıktı şablon modellerinden oluşmaktadır (Tablo 2).

Tablo 2. Parametrik Tasarım Montaj Yapısı

\begin{tabular}{ll}
\hline Kod & Açıllama \\
\hline Girdi & Araç koordinat sistemi \\
Hazırlık & Sürücü erişim mesafeleri \\
Çıktı & $\begin{array}{l}\text { H-noktası ve araç içi yolcu } \\
\text { yerleşimleri }\end{array}$
\end{tabular}

$\mathrm{Bu}$ yapının doğru oluşturulması çok karmaşık parametrik tasarımlarda dahi doğru sonuçların elde edilebilmesi için oldukça önemlidir. Oluşturulacak ve birbiriyle haberleşecek tüm şablonlar şekildeki montaj yapısına göre isimlendirilerek oluşturulmalıdır (Şekil 4).

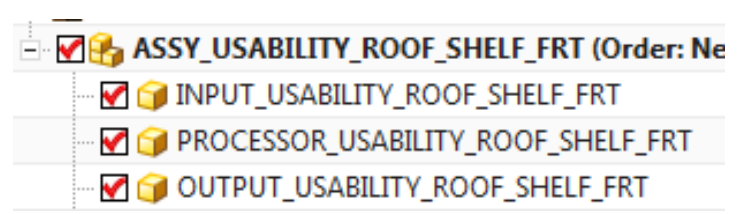

\section{Şekil 4. UG programındaki Parametrik Tasarım Montaj Yapısı}

Geliştirilen sistem ve uygulama örneği TCAE/UG tasarım programı ortamında Ticari araç modeli Fiat Doblo modeli için uyarlanmıştır. Aynı parametrik model, farklı ergonomi hedefleri olan projelerde bulunan diğer tavan eşya rafı ergonomi kontrollerinde de kullanılabilecektir.

\subsection{Girdi (Input)}

Parametrik tasarım yapısında bu bölüm, oluşturulacak şablonun haberleşmesi istenilen şablonların çıktı modelinden link alındığı, referans modellerin tanımlanabildiği ve şablona özel olan hedef değerlerin girilebildiği bir modeldir (Şekil 5).

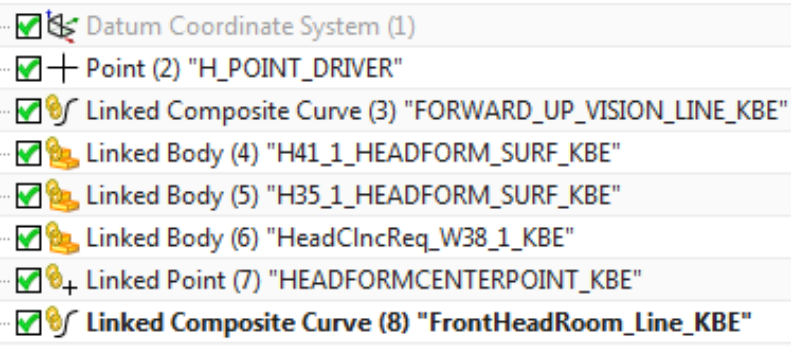

\section{Şekil 5. Girdi Modeli Ürün Ağacı Yapısı}

Parametrik model girdileri, sürücü H noktası, sürücü kafa boşluk değerleri ve sürücü görüş alanı değerleri ve proje ergonomi performans hedeflerinden oluşmaktadır (Şekil 6). 


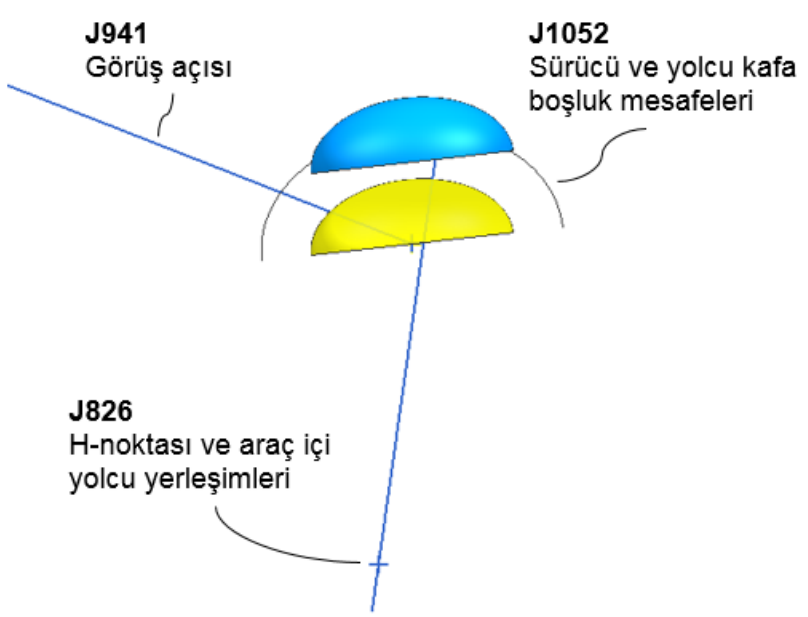

Şekil 6. Girdi Modeli Ekran Görüntüsü

\subsection{Hazırlık / Kurgu (Processor)}

Parametrik modelin kurgusunun yapıldığı ve kontrol sürecinde kullanılacak şablon tasarımının oluşturulduğu modeldir.

Sürücü görüş alanının belirlenmesi için kullanılan referans noktalar vardır. Bunlar yukarı ve aşağı görüş kısıtlamaları üç nokta ile ifade edilir. Üst gün ışığı açıklığı (DLO), alt gün ışığı açıklığı ve motor kapağı noktasıdır (Şekil 7) (Matthew, 2006).

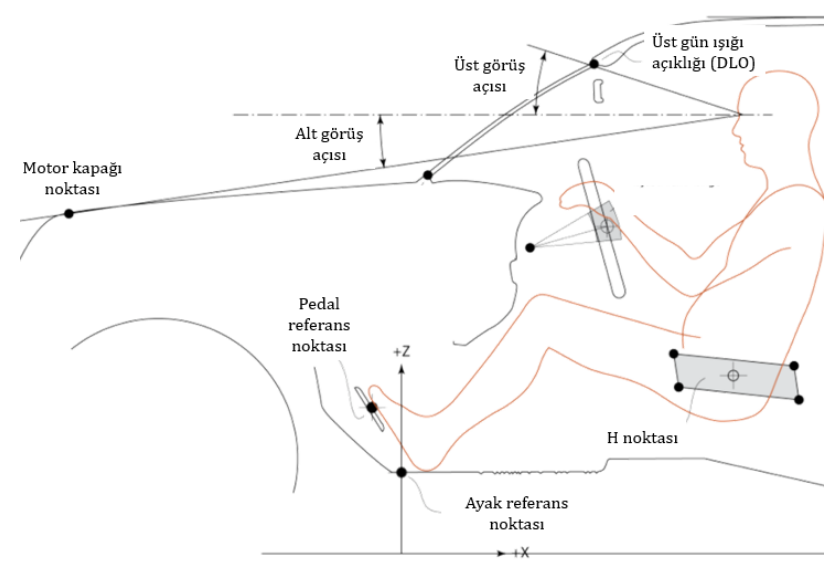

Şekil 7. Sürücü Görüş Alanının Belirlenmesi İçin Kullanılan Referans Noktaları

Girdi parametrik modelinden, sürücü H noktası, sürücü kafa boşluk değerleri ve sürücü görüş alanı değerlerine ait üst gün ışığı açıklığı (DLO) açı değeri ile proje ergonomi performans hedef değerleri hazırlık modelinden link alınmıştır (Şekil 8).

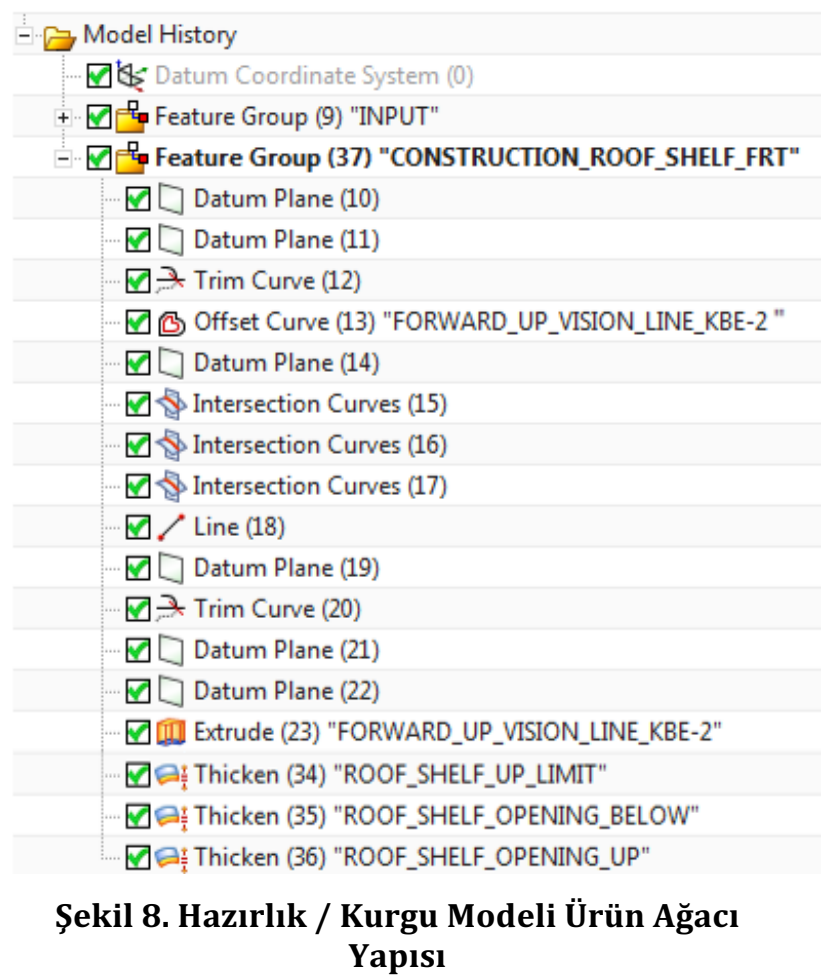

Tavan eşya rafının montajının yapılacağı tavan bölgesine ait bir referans model kesiti parametrik model içine eklenir. Referans kesit modelleri ve girdi modelinden alınan linkler doğrultusunda tavan eşya rafı için ergonomi hedefleri sınırları içinde kalan bir matematik model oluşturulmuştur (Şekil 9).

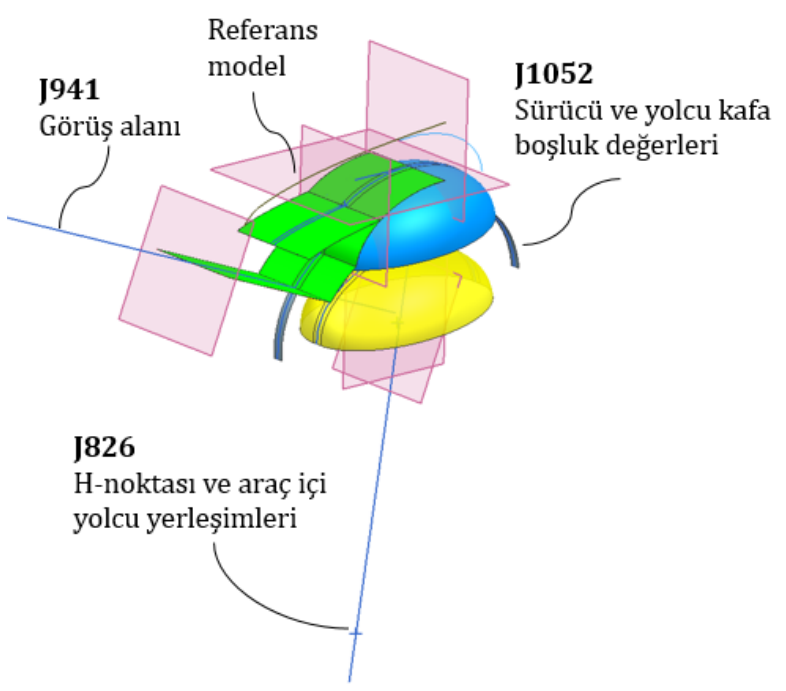

Şekil 9. Hazırlık / Kurgu Modeli Ekran Görüntüsü 


\section{4. Çıktı (Output)}

Çıtı modeli ergonomi analizinde kullanılacak şablonun elde edildiği modeldir. $\mathrm{Bu}$ model içine hazırlık modelinden kabin içinde araç sürücüsünün oturma pozisyonunu yansıtabilecek kafa boşluk değerleri, görüş alanı değerleri ve proje hedef değerlerine ilgili linkler alınır. Bu model ticari araç projesinde tavan eșya rafının ergonomi analizi yapacak kişi için kullanılabilecek referans bir şablondur. Şablon proje hedef değerlerinin değişmesiyle kendini güncelleyebilmektedir (Şekil 10).

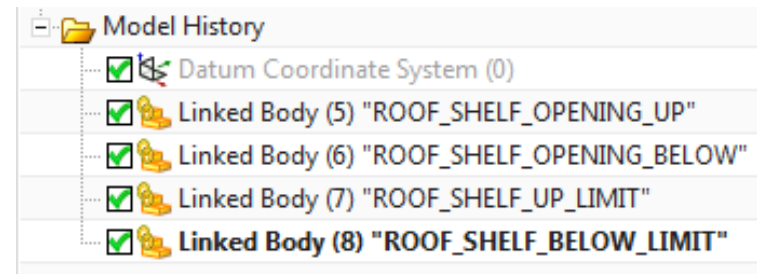

Şekil 10. Çıktı Modeli Ürün Ağacı Yapısı

Geleneksel kontrol yönteminde parametrik modelde mevcut olan tüm veriler manuel olarak UG programı içine girişinin yapılması gerekmektedir. Geliştirilen yöntemde ergonomi hedef değerleri parametrik model içine girilmesiyle sistem kendini otomatik olarak güncelleyebilmektedir ve oluşan şablon yardımıyla kontrol tamamlanabilmektedir (Şekil 11).

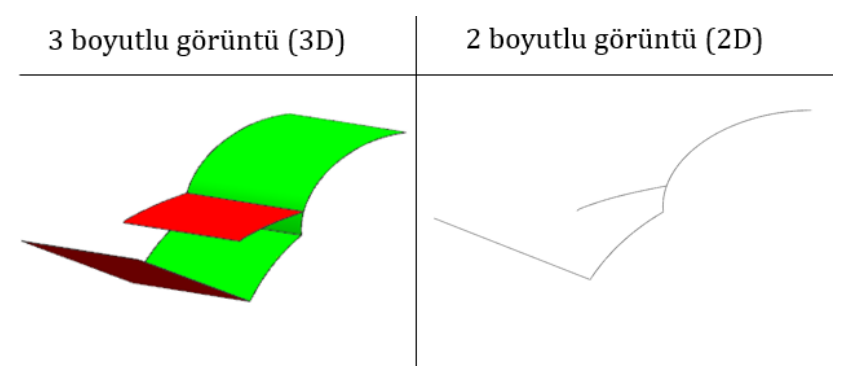

Şekil 11. Çıktı Modeli Şablon Ekran Görüntüsü

\section{Sonuçlar}

$\mathrm{Bu}$ çalışmada, bilgisayar destekli tasarım (CAD) programında ticari araçlarda kullanılan tavan eşya rafı için bilgi tabanlı mühendislik (KBE) yaklaşımıyla ergonomi kontrolünde kullanılabilecek bir parametrik şablon geliştirilmiştir. Şablon aracıllğıyla ergonomi doğrulama süreci kontrolü yapan farklı kişilerin çıtılarını standart hale getirilerek, yorumlamadan kaynaklı hatalar engellemiştir.

Kontrolü yapan kişi veya kişiler proje hedef değerlerini girdi modeline girişini yaparak veya mevcut olan değerleri yenileriyle güncelleyerek şablonu oluşturabilecektir (şekil 12). Güncelleme sürecinde hazırlık modelinde herhangi bir değişiklik yapılmasına ihtiyaç duyulmamaktadır. Geliştirilen parametrik şablon ile çıtı modelinin otomatik olarak güncellenmesi sağlanmaktadır.

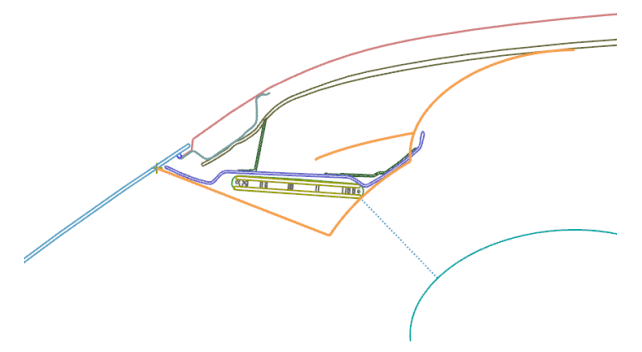

\section{Şekil 12. Çıktı Modelinde Tavan Eşya Rafı ve} Şablon Ekran Görüntüsü

Çalışma sonucunda geleneksel yöntemler kullanıldığı taktirde 18 saat süren kontrol için kontrol model tasarımı ve ardından sanal ortamda doğrulaması yapılmaktadır. Yeni geliştirilen parametrik model ile kontrol model tasarımı 0.5 saate düşürülmüştür. Tüm kontrol sürecinin tamamlanması ise 2 saattir. Geliştirilen şablon sayesinde elde edilen verim $\% 88$ 'dir.

Proje sürecinde manuel olarak yapılan ergonomi kontrolleri sırasında harcanan süreyi azaltmada ve kontroller sırasinda insan kaynaklı hataların azalmasından geliştirilen sistemin etkin bir şekilde kullanılabildiği saptanmıştır Geliştirilen sistemin akış şeması Şekil 13'de görülmektedir.

$\mathrm{Bu}$ çalışmada, geliştirilen sistem ile ergonomi alanında bilgi tabanlı mühendislik (KBE) yaklaşımıyla 62 adet parametrik şablon oluşturulmuştur ve tüm şablonlar birbiriyle haberleșebilmektedir. Geliștirilen sistem Fiat Doblo modeli referans alınarak tamamlanmıștır. Parametrik hale getirilmiş olan bu şablon, yeni yapılacak olan ticari araç projelerinde veya mevcut model üzerinde yapılacak değişiklikler için de kullanılabilecektir.

\section{Semboller}

$\begin{array}{ll}\text { BDT } & \text { Bilgisayar Destekli Tasarım } \\ \text { CAD } & \text { Computer Aided Design } \\ \text { KBE } & \text { Knowledge Base Engineering } \\ \text { DLO } & \text { Upper Daylight Opening } \\ \text { TCAE } & \text { Team Center Automotive Engineering } \\ \text { UG } & \text { Unigraphics } \\ \text { 2D } & 2 \text { boyutlu görüntü } \\ \text { 3D } & 3 \text { boyutlu görüntü } \\ \text { SAE } & \text { Society Automotive Engineers }\end{array}$




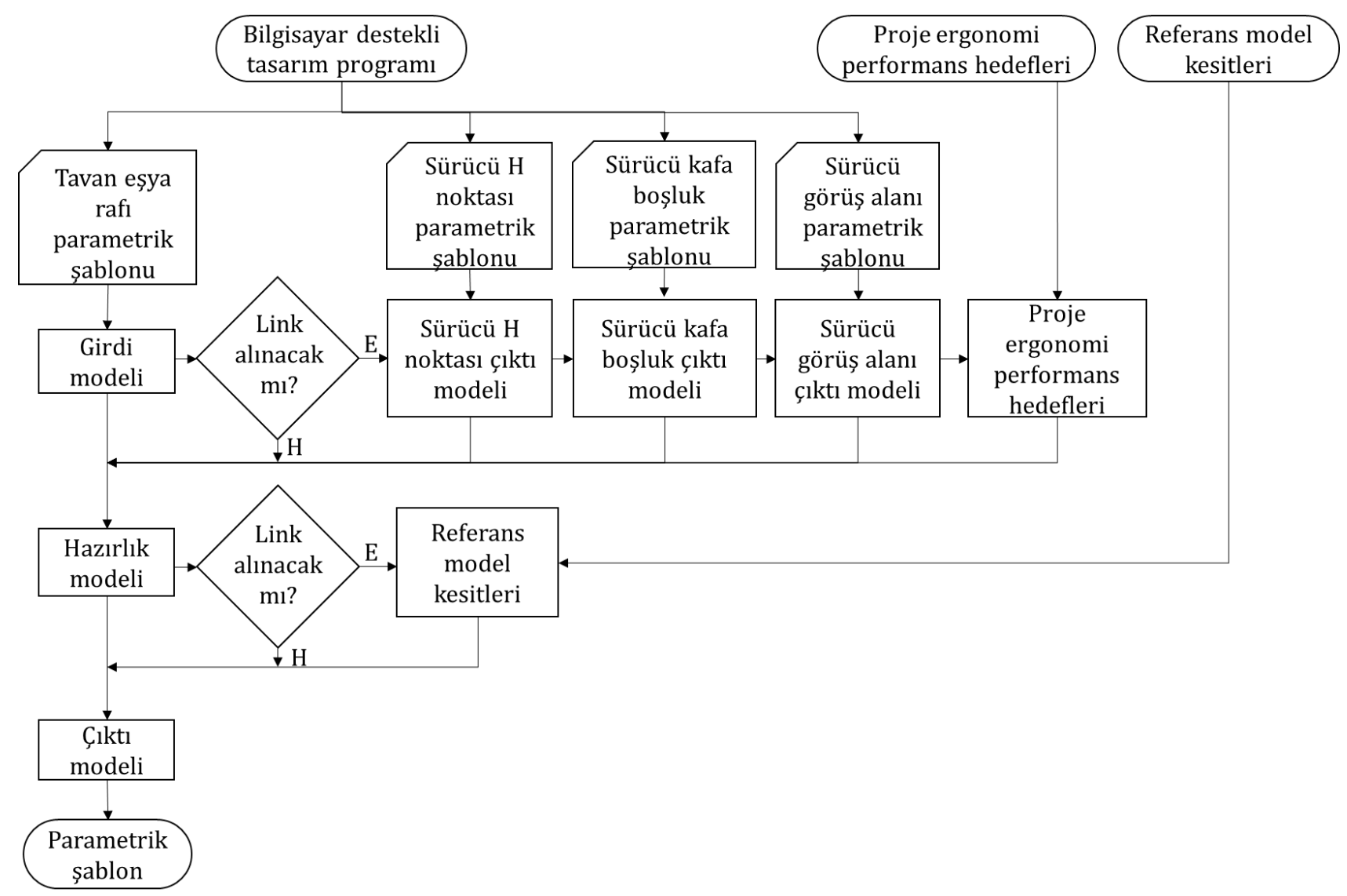

\section{Şekil 13. Parametrik Model Tasarımı Akıș Diyagramı}

\section{Teşekkür}

Bu çalışma, 3160665 proje kodlu "Bilgi Tabanlı Mühendislik Yaklaşımıyla Modüler Araç Tasarım" adlı proje kapsamında TÜBİTAK desteği ile gerçekleștirilmiştir. Yazarlar TÜBITTAK'a ve Tofaş Ar-Ge merkezine teşekkür etmektedirler.

\section{Çıkar Çatışması}

Yazarlar tarafından herhangi bir çıkar çatışması beyan edilmemiştir.

\section{Kaynaklar}

Aish, R. \& Woodbury, R. (2005). Multi-level Interaction in Parametric Design
Andrews, P. T. J, Shahin, T. M. M. \& Sviloganathan, S. (1999). Design Reuse in A Cad Enviroment - Four case studies

Doi: 10.1016/S0360-8352(99)00033-9

Bilgi Tabanlı Mühendislik Yaklaşımıyla Modüler Araç Tasarımı, TEYDEB Proje Kodu: 3160665

Camba, J. D. Contero, M. (2016). Parametric CAD modeling: An Analysis of Strategies For Design Reusability Bilimleri Enstitüsü, İstanbul. Doi: 10.1016/j.cad.2016001.003

Güler, S. (2016). Bilgi Tabanlı Mühendislik ve Ergonomik Otomobil Tasarımında Uygulaması. MBA Tezi, İstanbul Bilgi Üniversitesi Sosyal Bilimleri Enstitüsü, İstanbul.

Doi: 10.1016/j.cad.2016001.003

Kahraman, M. F. (2013). Türkiye`de Antropometrik Verilere Göre Ofiste Ergonomik İşyeri Tasarımı. İş Sağlığı ve Güvenliği Uzmanlık Tezi. Çalışma Ve Sosyal Güvenlik Bakanlığı İş Sağlığı Ve Güvenliği Genel Müdürlüğü, Ankara.

Karabıyık, Ö. (2011). Sac-Metal Kesme Kalıplarının Parametrik Tasarımına Yönelik Bir Yaklaşım. 
Ergonomi 3(1), 10 - 17, 2020

SDU International Technologic Science, Vol.3, No.

2, February 2011

Matthew, P. R. \& Ron, W. R. (1999). New Concept in Vehicle Interior Design Using Aspect, SAE Technical Paper Series.

Matthew, B. P. \& Matthew, P. R. (2006). Optimizing Vehicle Occupant Packaging, SAE Technical Paper Series (SAE J826),5,6.

Robinette, K. M. (2012). Anthropometry for Product Design.

Doi: $10.1002 / 9781118131350 . \operatorname{ch} 11$

Rocca, G. (2012). Knowledge Based Engineering: Between AI and CAD. Review of A Language Based Technology to Support Engineering Design.

Doi: 10.1016/j.aei.2012.02.002

Utanır, İ., Öztürk, Ö. ve Doruk, E. (2015). Araç Gövdesi Mimari Kesitlerinin Parametrik Tasarımı. Journal of Polytechnic.

Doi: 10.2339/2016.19.3 269-274

Yannick, B. (2013). A Roadmap For Parametric CAD Efficiency in The Automotive Industry. ComputerAided Design, Tata Technologies Europe, France, 1,5 .

Doi: 10.1016/j.cad.2013.05.006 